\title{
Life expectancy and healthy life expectancy of Japan: the fastest graying society in the world
}

Shinkan Tokudome ${ }^{1 *}$, Shuji Hashimoto ${ }^{2}$ and Akihiro Igata ${ }^{3}$

\begin{abstract}
Background: We appraised time trends of Japanese life expectancy (LE) and healthy life expectancy (HALE) by gender, LE-HALE and (LE-HALE)/LE figures, along with the women-men's differences.

Methods: Using the Japanese LE and HALE values from 1990 through 2013 by gender in the article by the GBD 2013 DALYs and HALE Collaborators, we examined trends of LE and HALE, and their 5- or 3-year changes. We also probed LE-HALE and (LE-HALE)/LE values, and the women-men's differences.

Results: LE consistently elongated as reported 76.0, 76.5, 77.6, 78.7, 79.3 and 80.1 years for men from 1990 to 2013; and 82.0, 82.8, 84.3, 85.5, 86.1 and 86.4 years for women, respectively. Both time trends demonstrated a significant linear increase ( $p$ for trend <0.001). LE changes were $0.4,1.1,1.1,0.7$ and 0.7 years for men, and $0.9,1.5,1.2,0.6$ and 0.3 years for women. The trends were statistically significant $(p<0.001)$, except for 2010-2013 partly due to 3-year interval. HALE also steadily lengthened as seen 68.1, 68.4, 69.1, 69.9, 70.8 and 71.1 years for men from 1990 through 2013; and 72.2, 72.9, 74.0, 74.8, 75.4 and 75.6 years for women. Both time trends showed almost a linear increase $(p<0.05)$. HALE changes were $0.4,0.6,0.8,0.9$ and 0.3 years for men, and $0.7,1.0,0.8,0.6$ and 0.2 years for women, without statistical significant trends. LE-HALE values were 8.0, 8.0, 8.5, 8.8, 8.6 and 8.9 years for men; and 9.7, 9.9, 10.4, 10.7, 10.7 and 10.8 years for women. (LE-HALE)/LE figures were 10.5, 10.5, 10.9, 11.1, 10.8 and $11.2 \%$ for men, and 11.9, $12.0,12.3,12.5,12.4$ and $12.5 \%$ for women. LE women-men's differences were 5.9, 6.4, 6.8, 6.8, 6.8 and 6.3 years, and the HALE figures were 4.2, 4.5, 4.9, 4.9, 4.6 and 4.5 years.

Conclusions: LE and HALE consistently linearly elongated for both sexes over the study period. Not only LE-HALE but also (LE-HALE)/LE values were still growing for both sexes. Public health measures, nursing-care/services as well as social security schemes are called for to further elevate longevities, HALE in particular, and enhance quality of life and well-being.
\end{abstract}

Keywords: Healthy life expectancy, Life expectancy, Non-communicable disease, Quality of death, Quality of life

\section{Background}

Global burden of disease (GBD) and global, regional, and national trends of life expectancy (LE) (the average number of years expected to live at birth) and healthy life expectancy (HALE) [LE taken into account disabilityadjusted life-years (DALYs) at birth, disability-free LE, or health-adjusted LE] [1] in the world from 1990 through

\footnotetext{
*Correspondence: tokudome2013@gmail.com

1 Department of Nutritional Epidemiology, National Institute of Health and Nutrition, 1-23-1, Toyama, Shinjuku-ku, Tokyo 162-8636, Japan Full list of author information is available at the end of the article
}

2013 were reported by the GBD 2013 DALYs and HALE Collaborators $[2,3]$. They provided valuable information on potential sociodemographic factors pertaining to the longevity figures and their transition, and demonstrated global perspectives for achieving sustainable development goals. In addition, they underscored the need for country- and sociodemographic group-specific assessments of the longevity values.

Approximately 70 years ago (in 1947), Japanese LE was only ca 50 years for men and 54 years for women [4]. In 2013, Japan attained not only the world's longest LE of 
80.1 years for men and 86.4 years for women, but also the highest HALE of 71.1 years for men and 75.6 years for women [2]. LE of $>80$ years for men was first achieved in Japan. HALE of $>70$ years was enjoyed by Japanese men along with the men of Singapore (70.8 years) for the first time worldwide.

Thus, it seems informative not only to note trends of LE and HALE by gender, their 5- or 3-year changes [that is, 5 years in length for the first 4 intervals, while 3 years for the last interval (2010-2013)], LE-HALE and (LEHALE)/LE figures, and their women-men's differences but also to discuss public health schemes, nursing-care services, and social security measures thus far implemented (or to be launched) for elevating longevities, HALE in particular, and realizing a better quality of life (QOL) and quality of death (QOD).

\section{Methods}

Using the Japanese LE and HALE figures by gender in 1990, 1995, 2000, 2005, 2010 and 2013 in the articles by the GBD 2013 DALYs and HALE Collaborators [2, 3], we probed trends of LE and HALE, along with 5-year changes of 1990-1995, 1995-2000, 2000-2005, 20052010 and 3-year change of 2010-2013. We also studied LE-HALE and (LE-HALE)/LE figures, and explored differences in LE and HALE between men and women.

\section{Statistical analyses}

On the basis of linear regression model, each trend of LE and HALE from 1990 through 2013 by gender was examined setting respective calendar years as independent variables in consideration of the survey time interval, and assuming the respective longevity indices weighted by inverse variance as dependent variables.

Using two-sample $\mathrm{z}$-tests, we statistically probed the 5- or 3-year differences of LE and HALE by gender from 1990 through 2013. Assuming LE and HALE are asymptotically distributed according to normal distribution, we estimated the 95\% UIs for LE-HALE and (LE-HALE)/LE values along with gender differences in LE and HALE and similarly examined respective differences.

We considered $p<0.05$ (two-tailed) as statistically significant.

\section{Results}

LE consistently elongated as reported 76.04, 76.45, 77.55, 78.66, 79.34 and 80.05 years for men from 1990 through 2013; and $81.96,82.84,84.32,85.48,86.09$ and 86.39 years for women, in that order (Table 1). Both time trends showed a linear increase, and both gradients were statistically significant ( $p$ for trend $<0.001$ ) (Fig. 1). LE 5-year changes (except for 2010-2013) were 0.4, 1.1, 1.1, 0.7 and 0.7 years for men, and $0.9,1.5,1.2,0.6$ and 0.3 years for women, with statistical significance $(p<0.001)$, but not for the last interval due partly to a 3-year difference and wider corresponding $95 \%$ UIs.

HALE also steadily lengthened as seen 68.09, 68.44, $69.08,69.89,70.78$ and 71.11 years for men from 1990 through 2013; and 72.24, 72.92, 73.95, 74.77, 75.41 and 75.56 years for women. Both time trends manifested almost a linear increase, and both gradients were statistically significant ( $p$ for trend $<0.05$ ). HALE 5-year changes (except for 2010-2013) were 0.4, 0.6, 0.8, 0.9 and 0.3 years for men, and $0.7,1.0,0.8,0.6$ and 0.2 years for women, without statistical significance.

LE-HALE values were 8.0, 8.0, 8.5, 8.8, 8.6 and 8.9 years for men from 1990 through 2013; and 9.7, 9.9, 10.4, 10.7, 10.7 and 10.8 years for women. (LE-HALE)/LE figures were $10.5,10.5,10.9,11.1,10.8$ and $11.2 \%$ for men, and 11.9, 12.0, 12.3, 12.5, 12.4 and $12.5 \%$ for women. LE women-men's discrepancies were 5.9, 6.4, 6.8, 6.8, 6.8 and 6.3 years, and the HALE figures were $4.2,4.5,4.9,4.9$, 4.6 and 4.5 years.

\section{Discussion}

Although there was an LE drop in 1995, being partly explained by the Great Hanshin-Awaji Earthquake with 6434 victims and three unidentified people [5], LE consistently elongated for both sexes from 1990 through 2013. LE may be determined in part by genetic diatheses, but mostly by modifiable chronic conditions, health behaviors, and socio-economic and environmental factors [6-9]. For further lengthening LE, the following potential factors are to be taken into account. The traditional well-balanced palatable Japanese cuisine has gradually been changing, but retaining higher salt consumption (10.9 g/day on average for men and $9.2 \mathrm{~g} /$ day for women in 2014) [10]. Abundant/imbalanced intakes of energy and nutrients (typically affluent/imbalanced consumption of fats and oils, milk and dairy products, and meat instead of fish/shell fish, but lower intake of calcium) seem to be compatible with enhancing trends of metabolic syndrome (obesity, hypertension, dyslipidemia, and insulin resistance). Smoking rates remain higher among industrialized countries $(32.2 \%$ in men and $8.5 \%$ in women), and tobacco-related cancers and diseases are (and will be) frequent. Although the prevalence of daily drinking is declining, only a small fraction of alcohol-dependent patients had received medical care $[10,11]$. Sedentary working style, physical inactivity, and greater motorization are prevailing $[10,12]$. The participation rates in annual health checkups in the workplace were high, but rather lower in the community, and population-based cancer screening for several sites (such as the stomach, lung, colorectum, and cervix uteri) stay lower. Mental/psychological health disorders (including 


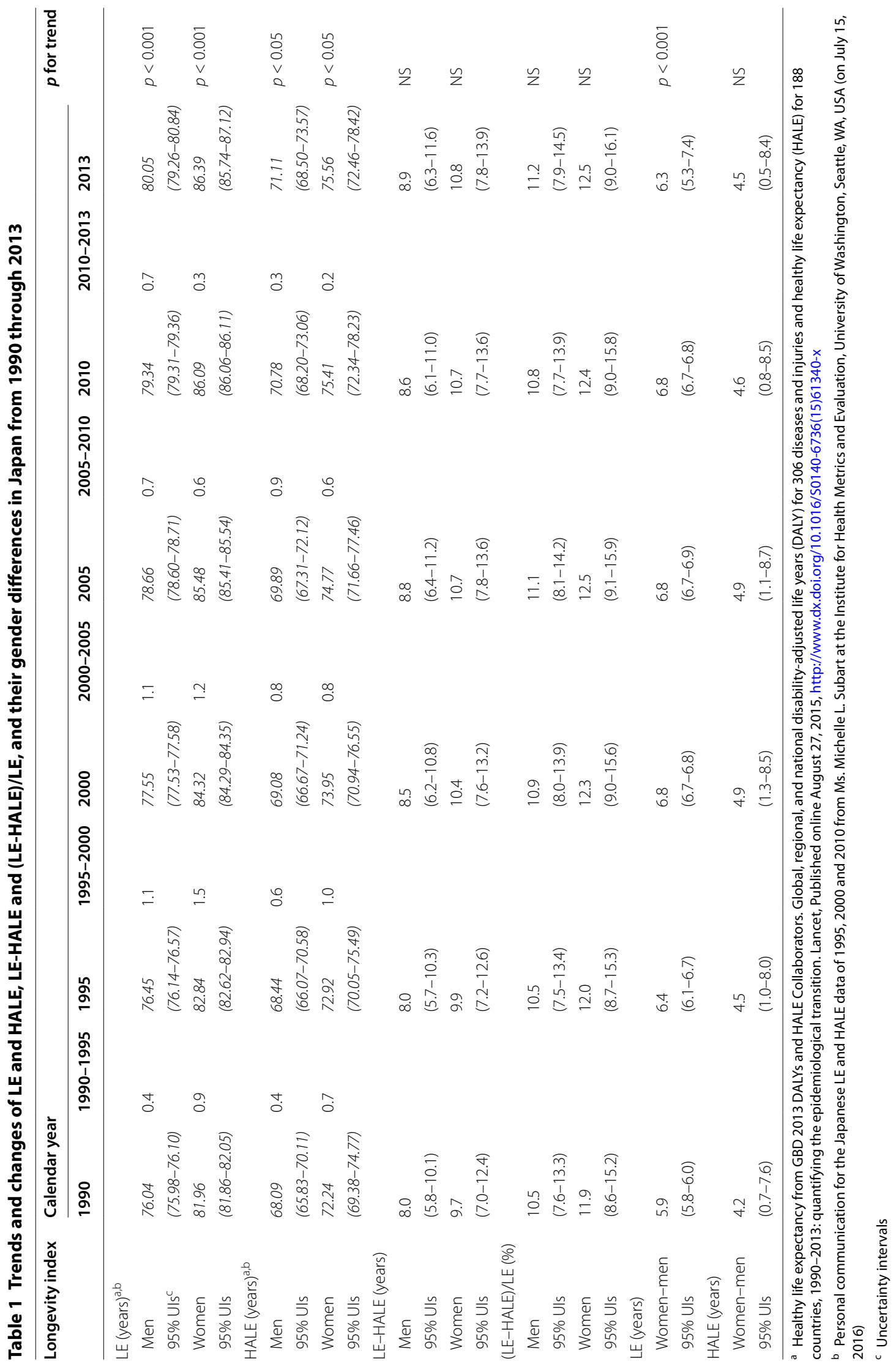



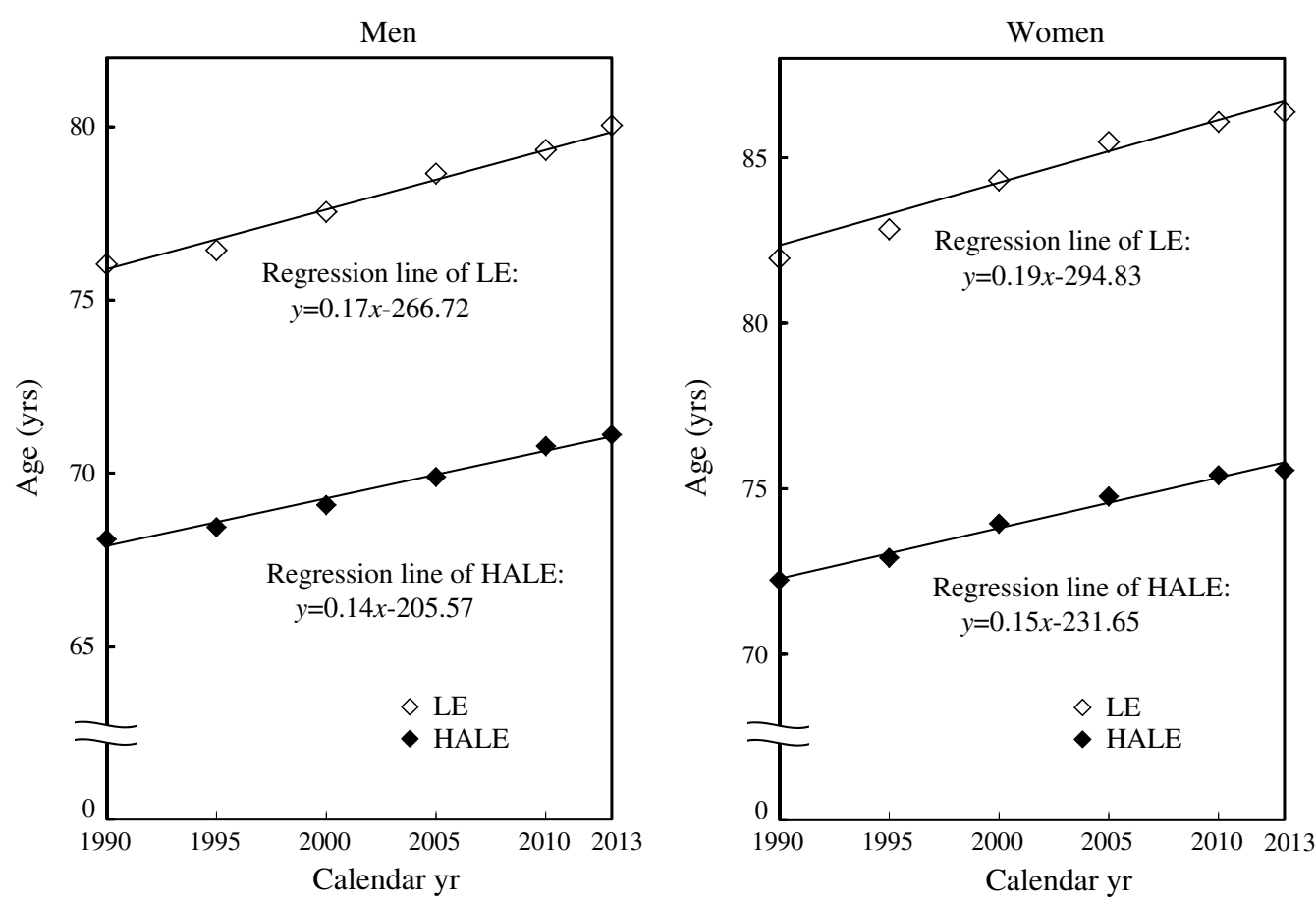

Fig. 1 Trends of LE and HALE of Japan from 1990 through 2013

depression) are big issues in the workplace due to overtime, stressful working environment and relationship dynamics within the workplace $[12,13]$.

HALE also manifested an upward increase for both sexes over the study period. Neither $p$ for trend nor the difference of regression coefficient between LE and HALE was significant, but LE-HALE and (LE-HALE)/LE values were steadily gaining, as also reported by Salomon and colleagues that "HALE increased more slowly than did LE [14]." Also of note is that LE-HALE and (LE-HALE)/ LE in women were greater than in men, which should be taken into account as they are directly involved in elderly women's QOL. In turn, Japan ranks high overall, ranking 8th, on the Global AgeWatch Index 2015 [15]. Favorable scores have been attained in two domains (Health domain [including longevities] and Capability domain), but have stayed behind in two domains (Income domain and Enabling societies and environment domain), manifesting age and gender inequities in working opportunity and income, coverage of pension and welfare, and hidden poverty [16]. Namely, HALE may be brought about by not only health-care and rehabilitation but also social security schemes, such as the Pension System, Long-term Nursing-Care, Health and Welfare Services, and Public Assistance [17]. Multi-phasic comprehensive interventions are called for to reduce years lived with disability (YLDs) (i.e., elongate HALE, and compress morbidity or
LE-HALE), because people should spend 8.9 YLDs (for men) and 10.8 YLDs (for women) (being more than $10 \%$ of the period of his/her life) in poor health.

The proportion of the elderly aged 65 years or over was ca $25 \%$ in 2013 , against $60 \%$ for working population aged 15-64 years [18]. The expenditure of benefits for the elderly group is steeply rising, and the burdens of work force and municipal/governmental finance are concurrently growing. Actually, the national health-care expenditure was Jpn Yen 40 trillion [ca US \$333 billion (under $1 \$=$ Jpn Yen 120)] in 2014, accounting for more than $40 \%$ of the national budget [19]. Japan is facing "the Year 2025 Problem," when two people in its work force should be able to support one elderly person, and the expenditure will be Jpn Yen 50 trillion (half of the national budget). By this year, as a typical delimiting of time, the baby-boomers will join the old group. Thanks to "low fertility and low mortality," it is forecast that the proportion of the elderly will be steadily growing, while that of the work force is tapering off, and the ratio is going to increase at least until 2060 [18]. The overall situation appears to be worsening as Japan is clearly moving towards an unheard-of super-aging crisis: too fast for Japanese society to catch-up with. In addition to innovative "core" structural reforms of the national administration and finance, reconstructions of social security plans must be executed, such as deferring 
of the retirement age, postponing the age for receiving pensions, advanced enrollment of "minorities" (the elderly and women), working on a regular basis, "equal labor, equal pay" for full-time and part-time workers, and effective/efficient use of Public Assistance for the needy elderly [20-22].

Japanese Universal Health Coverage (UHC) (Health Insurance for All, Nationwide Health Insurance Scheme) has largely contributed to enhance HALE as well as LE $[20,21]$. The UHC may be a global model of health-care for its low-cost with equity. However, continuing structural reforms of the UHC and health-care service systems have been made for the reduction of health-care costs, withholding of the elderly's health-care benefits, and so forth. Shared risk communication and securing a second opinion seem essential, but it is troublesome to realize that the UHC allows free and/or redundant (at times useless/unnecessary) visits to medical clinics/facilities, and repeated medical examinations and medicines [23]. The family/general physician system is developing, but the Medical Care Zone Scheme is not necessarily working well $[21,24]$. Using the Social Security and Tax Number System (My Number System) just enacted [25], the reduction of health-care costs could partly be achieved by record linkage with electronic health records to be stored in a unique IC card (or in cloud computing). Needless to say, this system must be launched under a national consensus, and should be handled under strict security and confidentiality.

QOL now includes several aspects; not only quality of biological life and quality of daily life but also quality of existence are of importance to fulfill one's life, to live and die with dignity, and to finally realize better QOD. Recently, the Economist Intelligent Unit of the UK Economist magazine ranked Japan's QOD index 2015 as 14th in the world [26]. The profiles of Japanese Affordability of care, Quality of care, and Community engagement were satisfactory, while those of Human resources and Palliative and health-care environment were rather unsatisfactory, so the ameliorations are urgent. Much remains to be improved in terms of QOD as well as HALE and QOL from the aspect of the well-being index of the elderly.

\section{Conclusions}

Japan has achieved the world's longest HALE as well as LE for both sexes in 2013. The increasing trends from 1990 through 2013, and significant changes were still being demonstrated. Not only long-term health-care strategies but also comprehensive community health promotion and social security services should be undertaken to further reduce mortality gap/health gap, elevate HALE, and enhance QOL and QOD in Japan.

\section{Abbreviations}

DALYs: disability-adjusted life years; GBD: global burden of disease; HALE: healthy life expectancy; LE: life expectancy; MHLW: Ministry of Health, Labour and Welfare; QOD: quality of death; QOL: quality of life; UHC: universal health coverage; UI: uncertainty interval; YLDs: years lived with disability.

\section{Authors' contributions}

ST collected and examined the data, and drafted the manuscript, SH analyzed the data, and Al critically read the manuscript. All authors read and approved the final manuscript.

\section{Author details \\ ${ }^{1}$ Department of Nutritional Epidemiology, National Institute of Health and Nutrition, 1-23-1, Toyama, Shinjuku-ku, Tokyo 162-8636, Japan. ${ }^{2}$ Fujita Health University School of Medicine, Toyoake, Japan. ${ }^{3}$ Nagoya University of Arts and Sciences, Nisshin, Japan.}

\section{Acknowledgements}

We are grateful to Ms. Michelle L. Subart at the Institute for Health Metrics and Evaluation, University of Washington, Seattle, WA, USA for providing the Japanese LE and HALE data of 1995, 2000 and 2010.

\section{Competing interests}

The authors declare that they have no competing interests.

\section{Availability of data and materials}

All data are available from the Reference \#2 and from the Institute for Health Metrics and Evaluation, University of Washington, Seattle, WA, USA.

Received: 26 February 2016 Accepted: 12 October 2016

Published online: 28 October 2016

\section{References}

1. Sullivan DF. A single index of mortality and morbidity. HSMHA Health Rep. 1971;86:347-54.

2. GBD 2013 DALYs and HALE Collaborators. Global, regional, and national disability-adjusted life years (DALY) for 306 diseases and injuries and healthy life expectancy (HALE) for 188 countries, 1990-2013: quantifying the epidemiological transition. Lancet. http://www.dx.doi.org/10.1016/ s0140-6736(15)61340-x. Accessed 27 Aug 2015.

3. Michelle L. Subart at the Institute for Health Metrics and Evaluation, University of Washington, Seattle, WA, USA. 2016 (personal communication).

4. Ministry of Health, Labour and Welfare, Japan. Japanese Life Tables. http:// www.mhlw.go.jp/toukei/list/list54-57.html. Accessed 3 Jan 2016.

5. Cabinet Office, Government of Japan. Causes of deaths from the Great Hanshin-Awaji Earthquake. http://www.bousai.go.jp/kaigirep/hakusho/ h23/bousai2011/html/honbun/2b_sanko_siryo_07.htm. Accessed 25 Jul 2016.

6. Hashimoto S, Kawado M, Yamada H, Seko R, Murakami Y, Hayashi M, et al. Gains in disability-free life expectancy from elimination diseases and injuries in Japan. J Epidemiol. 2012;22:199-204.

7. Ikeda N, Saito E, Kondo N, Inoue M, Ikeda S, Satoh T, et al. What has made the population of Japan healthy? Lancet. 2011;378:1094-105.

8. GBD 2013 Risk Factors Collaborators. Global, regional, and national comparative risk assessment of 79 behavioural, environmental and occupational, and metabolic risks or clusters of risks in 188 countries, 1990-2013: a systematic analysis for the Global Burden of Disease Study 2013. Lancet. 2015;. doi:10.1016/S0140-6736(15)00128-2 (Epub ahead of print).

9. Jagger $C$. Trends in life expectancy and healthy life expectancy. Future of an ageing population project: evidence review. London: Foresight, UK Government Office for Science; 2015. p. 1-29.

10. Ministry of Health, Labour and Welfare, Japan. Results of the National Health and Nutrition Survey, 2014. http://www.mhlw.go.jp/stf/houdou/0000106405.html. Accessed 3 Jan 2016.

11. Osaki Y, Kinjo A, Higuchi S, Matsumoto H, Yuzuriha T, Horie Y, et al. Prevalence and trends in alcohol dependence and alcohol use disorders 
in Japanese adults: results from periodical nationwide surveys. Alcohol Alcohol. 2016:51:465-73.

12. Ministry of Health, Labour and Welfare, Japan. Healthy People Japan, 21. http://www.1.mhlw.go.jp/topics/kenko21_11/top.html. Accessed 3 Jan 2016.

13. Ministry of Health, Labour and Welfare, Japan. Stress Check System according to the Partial Amendment of the Industrial Safety and Health Act. http://www.mhlw.go.jp/bunya/roudoukijun/anzeneisei12/ pdf/150422-1.pdf. Accessed $15 \mathrm{Jul} 2016$.

14. Salomon JA, Wang H, Freeman MK, Vos T, Flaxman AD, Lopez AD, et al. Healthy life expectancy for 187 countries, 1990-2010: a systematic analysis for the Global Burden Disease Study 2010. Lancet. 2012;380:2144-62.

15. Help Age International. Global AgeWatch Index 2015. http://www. helpage.org/global-agewatch/. Accessed 3 Jan 2016.

16. Organization for Economic Cooperation and Development OECD Health Statistics 2015. http://www.stats.oecd.org/index. aspx?DataSetCode=HEALTH_STAT. Accessed 16 Apr 2016.

17. Ministry of Health, Labour and Welfare, Japan. Public Assistance System. http://www.mhlw.go.jp/stf/seisakunitsuite/bunya/hukushi_kaigo/seikatsuhogo/seikatuhogo/. Accessed 3 Aug 2016.

18. Ministry of Health, Labour and Welfare, Japan. Problems of Elderly People. http://www.moj.go.jp/content/000123298.pdf. Accessed 18 Sept 2016.
19. Ministry of Health, Labour and Welfare, Japan. National Health Care Expenditure, 2013. http://www.mhlw.go.jp/toukei/saikin/hw/k-iryohi/13/ index.html. Accessed 3 Jan 2016.

20. Ikegami N, Yoo BK, Hashimoto H, Matsumoto M, Ogata H, Babazono A, et al. Japanese universal health coverage: evolution, achievements, and challenges. Lancet. 2011;378:1106-15.

21. Reich MR, Shibuya K. The future of Japan's health system-sustaining good health with equity at low cost. New Engl J Med. 2015;373:1793-7.

22. Ministry of Health, Labour and Welfare, Japan. National Health Insurance. http://www.mhlw.go.jp/file/06-Seisakujouhou-12400000-Hokenkyoku/0000072791.pdf. Accessed 25 Jul 2016.

23. Ministry of Health, Labour and Welfare, Japan. Survey of Patients' Behavior for Seeking Medical Care, 2008. http://www.mhlw.go.jp/toukei/saikin/ hw/jyuryo/09/index.html. Accessed 18 Sept 2016.

24. Ministry of Health, Labour and Welfare, Japan. Summary of National Health Care Plan. http://www.mhlw.go.jp/stf/shingi/2r9852000000zc42 att/2r9852000000zc72.pdf. Accessed 25 Jul 2016.

25. Ministry of Internal Affairs and Communications, Japan. Social Security and Tax Number System. http://www.soumu.go.jp/kojinbango_card/01. html. Accessed 1 Jan 2016.

26. Economist Intelligent Unit. The Economist. 2015 Quality of Death Index http://www.economistinsights.com/healthcare/analysis/quality-deathindex-2015. Accessed 3 Jan 2016.

\section{Submit your next manuscript to BioMed Central and we will help you at every step:}

- We accept pre-submission inquiries

- Our selector tool helps you to find the most relevant journal

- We provide round the clock customer support

- Convenient online submission

- Thorough peer review

- Inclusion in PubMed and all major indexing services

- Maximum visibility for your research

Submit your manuscript at www.biomedcentral.com/submit 